\title{
A INFLUÊNCIA DA GESTÃO DE PROJETOS NA CAPTAÇÃO DE RECURSOS EM MUNICÍPIOS ESTÂNCIAS: O CASO DA ESTÂNCIA TURÍSTICA DE PRESIDENTE EPITÁCIO
}

\author{
Suélen Daianne de Oliveira, Lechan Colares-Santos
}

Universidade do Oeste Paulista - UNOESTE, Curso de Especialização em Gestão de Projetos e Processos, Presidente Prudente, SP. E-mail: suelendaianne@hotmail.com

\section{RESUMO}

O presente artigo tem como objetivo demonstrar a influência da gestão de projetos na captação de recursos em municípios estâncias. Estes recursos são de significativa importância uma vez que proporcionam mais investimento em infraestrutura turística que impulsiona a atividade no município, e, com isso, movimenta a economia e possibilita a geração de empregos. Para tanto, foi efetuado um levantamento bibliográfico acerca do tema pesquisado e foram coletadas informações junto à prefeitura municipal sobre os investimentos realizados com recursos recebidos pelo DADE (Departamento de Apoio ao Desenvolvimento das Estâncias) nos anos de 2014 e 2015. Diante dos resultados, foi elaborado um comparativo com informações referentes aos anos de 2004 e 2005. Os resultados demonstram significativa perda de aquisição de recursos em vista ao número limitado de projetos aprovados, sendo possível inferir que há necessidade de capacitação dos recursos humanos no município estudado.

Palavras-chave: Gerenciamento de Projetos. Municípios Estâncias. Captação de Recursos. Gestão Pública. Recursos Públicos.

THE INFLUENCE OF PROJECT MANAGEMENT ON FUNDRAISING IN MUNICIPALITIES RESORTS: THE CASE OF THE TOURIST RESORT OF PRESIDENTE EPITÁCIO.

\begin{abstract}
This article aims to demonstrate the influence of project management on fundraising in municipalities resorts. These funds are of significant importance since they provide more investment in tourism infrastructure that boosts the activity in the municipality, and thereby moves the economy and enables the generation of jobs. Thus, it was made a literature review on the subject researched and information was collected at the municipal government about investments made with funds received by DADE (Department for Development Support of Resorts) in the years 2014 and 2015. Facing the results, it was prepared a comparative report with information referring to the years 2004 and 2005. The results show significant loss of fundraising given the limited number of approved projects and it is possible to infer that there is a need for human resources training in the city studied.
\end{abstract}

Keywords: Project Management. Municipalities Resorts. Fundraising. Public Management. Public Funds. 


\section{INTRODUÇÃO}

São inúmeros os desafios encontrados pelos gestores públicos municipais para atender as necessidades do município. Em se tratando de gestão de estâncias turísticas é importante que o município esteja preparado e em boas condições para receber bem o turista, e, para isso, é necessária a captação de recursos para realizar investimentos em infraestrutura turística. A liberação de recursos públicos do governo estadual para municípios estâncias acontece após a aprovação de projetos. Deste modo, podemos constatar a importância do conhecimento de gestão de projetos na administração de órgãos públicos.

Gestores públicos são responsáveis por administrar grandes volumes de recursos financeiros que necessitam de projetos bem elaborados para alcançar as respectivas finalidades para os quais foram criados. A elaboração, o acompanhamento e o controle na execução dos projetos são fundamentais para uma boa gestão dos recursos públicos. O objetivo deste estudo foi retratar a influência do gestor de projetos em organizações públicas, em especial em municípios estâncias, bem como realizar um levantamento sobre os projetos apresentados pelo município de Presidente Epitácio nos últimos dois anos. Para tanto, foi realizado uma contextualização teórica acerca da gestão de projetos nas organizações; em seguida, realizou-se uma abordagem geral sobre a transferência de recursos para municípios estâncias; e, por último, uma análise sobre os projetos realizados pelo município de Presidente Epitácio.

\section{MÉTODOS E PROCEDIMENTOS}

O presente trabalho foi desenvolvido utilizando como procedimento a pesquisa bibliográfica. Segundo Gil (1994) a pesquisa bibliográfica possibilita alcançar uma gama de informações dispersas em inúmeras publicações que auxiliam na construção ou na melhor definição do conceito que envolve o objeto de estudo proposto.

Para a realização desta pesquisa buscou-se levantar informações junto a Secretaria Municipal de Finanças do Município de Presidente Epitácio, bem como em livros, artigos científicos, dissertações, site oficiais, entre outros. Desta forma, possibilitou o levantamento de informações sobre o tema pesquisado e a análise dos recursos disponibilizados para o município no período estudado. Sendo assim, foi possível realizar uma comparação com as mesmas informações referentes aos anos de 2004 e 2005 levantadas em uma dissertação. A coleta de informações gerou dados secundários e tabelas, importantes para a melhor compreensão de alguns fatores.

\section{PRESSUPOSTOS TEÓRICOS}

\section{A GESTÃO DE PROJETOS NAS ORGANIZAÇÕES}

A gestão de projetos pode ser definida como o planejamento e o controle de uma série de atividades integradas de forma a atingir seus objetivos com êxito, para benefício dos participantes do projeto. Segundo Kerzner (2006) as empresas passaram a reconhecer a importância da gestão de projetos para garantir o sucesso dos negócios. Porém, a gestão de projetos é uma área da administração que pode ser aplicada tanto na iniciativa pública quanto na privada.

Ao nos referirmos a gestão de projetos na administração pública, primeiramente precisamos compreender que o objetivo dos órgãos públicos é atender aos interesses da sociedade, ou seja, gerir buscando o bem comum e a satisfação dos cidadãos. O gerenciamento de projetos na administração pública pode contribuir no alcance deste objetivo, porém, é preciso que as ações governamentais sejam planejadas e que os agentes públicos sejam qualificados.

Sem dúvida o gerenciamento de projetos em uma organização pública é bastante diferente de uma empresa particular. Órgãos públicos sofrem muita influência de leis e princípios, como por exemplo, o princípio da legalidade, isto é, todos os atos da Administração têm que estar em conformidade com os princípios legais. Além disso, na administração pública só é permitido fazer 
o que é regulamentado por lei, ou seja, as determinações para a execução do projeto estão préestabelecidas, enquanto que na iniciativa privada só não se pode fazer o que a lei proíbe, proporcionando mais flexibilidade de planejamento para o gestor (COELHO et al, 2014).

Além desses, podemos citar outros elementos que os tornam diferentes como: os objetivos, público-alvo, fiscalização, seleção de profissionais, orçamento e fonte de recursos. Pode-se destacar a distinção na motivação de realização de projetos, diferentemente de organizações privadas, em órgãos públicos não é o retorno financeiro, mas o retorno social. É importante ressaltar que para o bom gerenciamento de projetos em organizações públicas o gerente precisa ter domínio das leis aplicáveis ao orçamento público, são elas: Plano Plurianual (PPA), Lei de Diretrizes Orçamentárias (LDO), Lei Orçamentária Anual (LOA) e Lei de Responsabilidade Fiscal (LRF).

Realizar o planejamento é essencial na gestão de projetos, e, mesmo diante de diversas peculiaridades e limitações orçamentárias existentes em organizações públicas, a gestão de projetos pode trazer inúmeros benefícios, pois permite controlar as variáveis relacionadas ao desenvolvimento do empreendimento, como tempo e custos para execução das atividades. No entanto, é necessário que os envolvidos sejam profissionais preparados para a atuação na gestão de projetos.

O gerenciamento de projetos agrega qualidade à gestão, transformando planejamento em resultados e busca as melhores alternativas para a alocação de recursos. A implantação de práticas de gerenciamento de projetos em órgãos públicos pode também aumentar a eficiência e a qualidade nos serviços oferecidos a população. $O$ gerente de projetos tem um papel fundamental para o sucesso do projeto, ou seja, para a efetivação do empreendimento é necessária uma gestão eficaz, que saiba coordenar e integrar as atividades, capaz de orientar e fornecer direcionamento para a execução das ações.

\section{TRANSFERÊNCIA DE RECURSOS PARA OS MUNICÍPIOS ESTÂNCIAS}

No estado de São Paulo existem setenta municípios considerados estâncias. Conforme suas características se classificam em balneárias, climáticas, hidrominerais e turísticas. Pelo fato de cumprirem determinados pré-requisitos definidos por lei estadual, adquiriram o direito de agregar, junto a seu nome o título de Estância Balneária, Turística, etc. "As Estâncias Turísticas são cidades com muitas tradições culturais, patrimônios históricos, artesanatos, lindas paisagens, centros de lazer, além de ótimos serviços de gastronomia" (SÃO PAULO. Secretaria de Turismo, 2016).

Os municípios estâncias recebem uma verba maior do governo do estado para ser investida em infraestrutura voltada para o turismo. O órgão responsável por fazer este repasse é o DADE Departamento de Apoio ao Desenvolvimento das Estâncias - criado no ano de 1989. Entre suas principais atribuições destaca-se a transferência de recursos diretos para a execução de obras e programas ligados ao desenvolvimento do turismo (SÃO PAULO. Secretaria de Turismo, 2016).

Os recursos repassados pelo DADE provém do Fundo de Melhoria das Estâncias.

A receita que o Fundo disponibiliza para os municípios é composta pela somatória dos Impostos Municipais de todas as estâncias por meio da apresentação de seu DREMU (Declaração de Receita Tributária Própria Municipal). Há também uma dotação oriunda do Governo do Estado no próprio Plano Plurianual (SÃO PAULO. Secretaria de Turismo, 2016).

O DADE disponibiliza recursos financeiros todos os anos para as estâncias, porém, para recebê-los os municípios devem determinar os objetos dos convênios a serem celebrados e os mesmos devem ser apresentados por meio de Planos de Trabalho. Caso sejam aprovados, a prefeitura desenvolve um projeto no qual deve ser explicado detalhadamente todo o valor que 
será recebido. A partir deste momento o projeto passa por uma vistoria pelos técnicos e, se for aprovado, os recursos começam a ser liberados para as prefeituras.

Porém, um dos principais problemas que vários municípios enfrentam é a falta de projetos que atendam as normas legais. Diante disso, fizeram uma alteração nos procedimentos de liberação de recursos. Agora, a verba é liberada por etapas (e não de forma global), à medida que as obras avançam, para evitar que o dinheiro seja repassado e a obra não seja concluída (SÃO PAULO, AGEM, 2015).

O recebimento dessa verba proporciona benefícios que impulsionam o setor turístico. Com mais investimentos é possível alavancar a economia, gerar mais empregos e melhorar a qualidade de vida da população local. Contudo, existem cidades que nunca apresentaram projetos para obtenção de recursos, como é o caso da Estância Balneária de Iguape (SÃO PAULO, AGEM, 2015).

Para conseguir receber os recursos financeiros é necessário que a equipe domine técnicas de gestão de projetos, pois o órgão responsável exige a explicação detalhada do objeto do convênio e todo o valor a ser disponibilizado para a prefeitura precisa ser especificado minuciosamente por meio de prestação de contas, e após a conclusão do projeto é necessário comprovar o cumprimento das obrigações assumidas. Caso essas regras não sejam cumpridas, o município fica impedido de receber novas verbas até que as prestações de contas do projeto anterior sejam regularizadas. Lück argumenta que, em casos onde projetos são condições para liberação de recursos, quase não existe preocupação com os resultados dos projetos, o foco tornase somente a aplicação dos recursos.

Sendo assim, vislumbra-se a importância de um profissional capacitado, pois a gestão dos projetos busca garantir a realização dos objetivos almejados dentro dos prazos, custos, qualidade e especificações definidas. Busca também direcionar esforços para atender às necessidades dos stakeholders $^{1}$ e lidar com as mudanças ao longo da sua realização.

\section{RESULTADOS E DISCUSSÕES O MUNICÍPIO DE PRESIDENTE EPITÁCIO}

Presidente Epitácio teve origem na necessidade da construção de uma estrada que ligasse o "sertão desconhecido" e desabitado de parte do Estado de São Paulo, com o sul de Mato Grosso (atual Mato Grosso do Sul) (MORONI, 2011, p. 30). Tornou-se município em 27 de março de 1949, entretanto, recebeu o título de Estância Turística somente em 20 de julho de 1990.

A população do município, segundo o censo do Instituto Brasileiro de Geografia e Estatística (2010) é de 41.318 pessoas, distribuídas em uma área de $1.259 \mathrm{~km}^{2}$. A economia no município tem como base a indústria, o comércio e a prestação de serviços, conforme apresentado na tabela a seguir:

\footnotetext{
${ }^{1}$ Pessoas e organizações, como clientes, patrocinadores, organizações executoras e o público, que estejam ativamente envolvidas no projeto ou cujos interesses possam ser afetados de forma positiva ou negativa pela execução ou término do projeto. Elas podem também exercer influência sobre o projeto e suas entregas (PMI, 2004, p. 371).
} 
Tabela 01. Ocupação no município de Presidente Epitácio por atividade econômica

\begin{tabular}{l|c}
\hline Atividade econômica & $\%$ \\
\hline Prestação de serviços & 44 \\
\hline Comércio & 30,45 \\
\hline Indústria & 20,52 \\
\hline Agropecuária, Produção Florestal, Pesca e Aquicultura & 4,01 \\
\hline Construção & 1,02 \\
\hline Total & $\mathbf{1 0 0}$ \\
\hline
\end{tabular}

Fonte: Seade/2014

A responsabilidade de fomentar o turismo no âmbito municipal é da Secretaria de Turismo e Cultura, que entre suas competências estão: planejar, organizar e criar mecanismos para o desenvolvimento das atividades turísticas do município (PRESIDENTE EPITÁCIO. Secretaria de Turismo e Cultura, 2016).

Foi realizada uma consulta junto a Secretaria de Finanças do município para descobrir o total de recursos recebidos do DADE nos últimos dois anos. Averiguou-se que no ano de 2014 foi transferido o total de $\mathrm{R} \$ 1.876 .887,55$ e no ano de $2015 \mathrm{R} \$ 1.272 .634,31$. A tabela abaixo descreve os projetos realizados.

Tabela 02. Recursos financeiros recebidos do DADE nos últimos dois anos

\begin{tabular}{c|l|c}
\hline \multicolumn{2}{c}{ Projeto } & Valor recebido do DADE \\
\hline 1 & Plano Diretor de Turismo & $\mathbf{7 4 . 8 4 6 , 6 7}$ \\
\hline 2 & Infraestrutura em vias do município & $575.096,89$ \\
\hline 3 & Reformulação da Fonte da Praça da Matriz & $541.841,81$ \\
\hline 4 & Infraestrutura em vias públicas & $685.102,18$ \\
\hline \multicolumn{2}{c}{ Total } & $\mathbf{1 . 8 7 6 . 8 8 7 , 5 5}$ \\
\hline \multicolumn{2}{c}{ Projeto } \\
\hline \multicolumn{2}{c}{ 2015 } \\
\hline 2 & Infraestrutura em vias do município & $590.156,35$ \\
\hline & Infraestrutura em vias públicas & $\mathbf{1 . 2 7 2 . 6 3 4 , 3 1}$ \\
\hline
\end{tabular}

Fonte: Secretaria de Finanças da Prefeitura Municipal da Estância Turística de Presidente Epitácio, 2016.

Como se pode observar houve uma queda de $32,20 \%$ no total de repasses para o município no ano de 2015 em comparação com o ano anterior. Porém, se efetuarmos um comparativo com os repasses dos anos de 2004 e 2005, houve um crescimento de $54,25 \%$ (em comparação com os repasses de 2004 e 2014) e de 88,33\% (em comparação com os repasses de 2005 e 2015), conforme podemos observar pelos projetos apontados na tabela a seguir: 
Tabela 03. Recursos financeiros recebidos do DADE nos anos de 2004 e 2005

\begin{tabular}{l|l|c}
\hline \multicolumn{2}{c}{ Projeto } & Valor recebido do DADE \\
\hline 1 & Pista de atletismo & $\mathbf{7 3 . 4 7 6 , 4 8}$ \\
\hline 2 & Reestruturação dos canteiros centrais & $175.000,00$ \\
\hline 3 & Posto de Informações Turísticas & $85.000,00$ \\
\hline 4 & Pavimentação asfáltica & $519.268,00$ \\
\hline \multicolumn{2}{c}{ Total } & $\mathbf{8 5 2 . 7 4 4 , 4 8}$ \\
\hline \multicolumn{2}{c}{ Projeto } \\
\hline \multicolumn{2}{c}{$\mathbf{2 0 0 5}$} \\
\hline 1 & Revitalização da Praça da Igreja Matriz & Valor recebido do DADE \\
\hline 2 & lluminação de trevo & $\mathbf{7 0 . 0 0 0 , 0 0}$ \\
\hline & Total & $\mathbf{1 4 8 . 5 5 1 , 1 8}$ \\
\hline
\end{tabular}

Fonte: BOMFIM, 2007.

No entanto, mesmo apresentado uma melhora significativa com relação aos recursos recebidos nos anos de 2004 e 2005 o ideal é que estes recursos continuem crescendo para mais investimento em infraestruturas no município.

Também é necessário que mais projetos sejam aprovados para a liberação de recursos. Em 2015, apenas dois projetos garantiram a verba do DADE. Este é um número bastante pequeno com relação a tantas necessidades que existem no município.

\section{CONSIDERAÇÕES FINAIS}

A liberação de recursos financeiros para os municípios estâncias é realizada somente a partir da aprovação de projetos elaborados de acordo com os padrões estabelecidos pelo DADE.

O recebimento dessa verba é muito importante para um município como Presidente Epitácio, carente de investimentos em infraestrutura, no qual a renda que movimenta a economia refere-se, principalmente, a prestação de serviços e ao comércio.

Entretanto, observou-se que houve uma queda na quantidade de projetos aprovados pelo DADE, e, consequentemente, no valor repassado para a prefeitura entre os anos de 2014 e 2015, o que refletiu em menos investimentos no município. A gestão pública para ser eficaz depende da implementação de projetos, os quais possibilitam a realização de obras e melhorias para o município. Diante disso, surge o questionamento se a prefeitura municipal está estruturada, com recursos humanos capacitados para garantir os recursos financeiros disponíveis para os municípios estâncias. Pode-se observar que existe uma carência de conhecimentos na área de gestão de projetos, o que está impedindo a prefeitura de usufruir as verbas disponibilizadas pelo governo, já que para recebê-las é necessária a elaboração de projetos. Os recursos humanos precisam ser capacitados para que tenham condições de captar mais recursos financeiros e assim realizar mais investimentos no município.

Com isso, este trabalho procurou demonstrar como o Gerente de Projetos pode contribuir na administração pública, em busca de resultados eficazes e atendimento das necessidades da população.

\section{REFERÊNCIAS}

BOMFIM, Luiz C. E. O turismo como alternativa de desenvolvimento local no município de Presidente Epitácio: representações socias e culturais de identidade local. 2007. 102 f. Dissertação (Mestrado em Desenvolvimento Local) - Universidade Católica Dom Bosco, Campo Grande-MS. 
COELHO, Romney M. et al. Gestão de projetos no setor público: legislações orçamentárias. In: SINGEP - SIMPÓSIO INTERNACIONAL DE GESTÃO DE PROJETOS, INOVAÇÃO E SUSTENTABILIDADE, 4., 2015, São Paulo. Anais do IV Singep. São Paulo, 2015. Disponível em:

<http://www.singep.org.br/4singep/resultado/344.pdf>. Acesso em: 27 de maio de 2016.

IBGE - Instituto Brasileiro de Geografia e Estatística. Presidente Epitácio. Disponível em: <http://www.cidades.ibge.gov.br/xtras/perfil.php?lang=\&codmun=354130\&search=saopaulo|presidente-epitacio>. Acesso em: 14 de maio de 2016.

GIL, Antonio C. Métodos e técnicas de pesquisa social. São Paulo: Atlas, 1994.

KERZNER, Harold. Gestão de Projetos: As melhores práticas. 2.ed. Porto Alegre: Bookman, 2006.

LÜCK, Heloisa. Metodologia de projetos: uma ferramenta de planejamento e gestão. 9. ed. Petrópolis: Vozes, 2013.

MORONI. Benedito de G. História de Presidente Epitácio. 2. ed. Maringá: Edição do autor, 2011.

PMI - Project Management Institute. Um guia do conhecimento em gerenciamento de projetos: guia PMBOK. 3. ed. Newtown Square: Project Management Institute, 2004.

PRESIDENTE EPITÁCIO. Secretaria de Turismo e Cultura. Disponível em: <http://www.presidenteepitacio.sp.gov.br/?pagina=turismo.html>. Acesso em: 14 de maio de 2016.

SÃO PAULO. AGEM. Alteração faz verbas Dade caírem R\$ 14,2 milhões na Baixada. Disponível em: <http://www.agem.sp.gov.br/alteracao-faz-verbas-dade-cairem-r-142-milhoes-na-baixada/>. Acesso em: 27 de maio de 2016.

SÃO PAULO. SEADE. Informações dos municípios paulistas. Disponível em: <http://www.imp.seade.gov.br/frontend/\#/perfil>. Acesso em: 14 de maio de 2016.

SÃO PAULO. Secretaria de Turismo. Estâncias. Disponível em: <http://www.turismo.sp.gov.br/dade/estancias.html> Acesso em: 14 de maio de 2016. 